\section{Human embryonic stem cell research in the US: time for change?}

\section{US President Barack Obama has reversed some barriers to human embryonic stem cell research, but much remains to be done to ensure that stem cell research flourishes in the US in the coming decades.}

In March 2009, President Obama issued an executive order intended to bolster human embryonic stem (hES) cell research in the United States. Despite this announcement, federal support and funding for hES cell studies lags behind programmes in many other countries, and the continually evolving federal policies have further stymied research efforts. Former President Clinton signed a law in 1995 banning federal funding for research that would destroy human embryos, which barred researchers supported by US National Institutes of Health (NIH) grants from creating new hES cell lines. Such a ban has been renewed by the US Congress every year since. In 2001, the Bush administration then restricted the number of hES cell lines that could be used in federally funded research to just 21 viable lines. President Obama's executive order overturned these Bush-era constraints, and federal funds can now be used for research on any hES cell line that is found to meet the NIH's strict ethical policies. However, it is still not possible to create new hES cell lines from viable embryos using federal funds, and verifying that hES cell lines were derived from donors who provided informed consent - which is essential for NIH approval - has proven to be extremely time consuming. Thus, the extent to which US stem cell researchers have truly benefited from these more relaxed funding policies is questionable.

As the July issue of this journal went to press, 64 hES cell lines were eligible to be used in research supported by US federal funds. Although over 300 additional hES cell lines (created in institutes in Europe or Asia, or by US researchers with private or state-based funding) are awaiting NIH review or are in the review submission process, it is unclear when or how many of these lines will be added to the registry. George Daley (Children's Hospital Boston) notes that although researchers have greatly benefitted from the availability of additional hES cell lines, the slow process of approving existing hES cell lines and, significantly, the inability to derive new hES cell lines, are major obstacles. By contrast, 120 hES cell lines are available through the UK Stem Cell Bank registry and new hES cell lines can be created in the UK subject to licensing by the Human Fertilization and Embryology Authority (HFEA). China, Japan and some European countries, notably Belgium and
Sweden, have similarly liberal policies regarding the creation of new hES cell lines.

Although it is possible that the number of NIH-approved hES cell lines will eventually be sufficient for general laboratory research, in the interim, many researchers have turned to induced pluripotent stem (iPS) cells, which can be made and studied using NIH funds as they are not prepared from human embryos. However, accumulating evidence suggests that iPS cells derived from adult somatic tissues are not functionally equivalent to hES cells, and as such their relevance to disease is unclear. According to Robin Lovell-Badge (UK National Institute for Medical Research), the creation of new hES cell lines is essential not only to address basic questions in development and disease, but to test and implement technical improvements in culture conditions that might affect hES cell viability and pluripotency. To allow US researchers to remain competitive in these areas, the government must enact an ethically sound federal policy, administered by a governmental regulatory agency, to permit the creation of additional hES cell lines with NIH funds, as the HFEA does in the UK.

In light of the limits to federal funding access for hES cell research, philanthropic organizations and some state governments have stepped in to support hES cell research. In November 2004, voters in California approved a proposition that established the California Institute for Regenerative Medicine (CIRM), which was initially endowed with US\$3 billion ( $£ 2$ billion) in state funds, to support research on hES and human adult stem cells. Unlike grants from the $\mathrm{NIH}$, grants from the CIRM can be used to create new hES cell lines and conduct research on lines that have not yet been approved by the NIH. The CIRM also engages in partnerships with institutions around the world, allowing California's hES cell researchers to establish international collaborations. Several other states, including Connecticut, Illinois, Maryland, Massachusetts, New Jersey, New York and Ohio, have developed programmes intended to support hES cell research; however, voters have been reluctant to approve funding for some of these state initiatives, and philanthropic donations to stem cell research institutes have suffered from the economic recession.

With the passage of the American Recovery and Reinvestment Act of 2009 and the small but important annual increases in the NIH budget, the US Congress and Obama administration have taken steps to shore up the overall federal budget for scientific research. For this commitment to be significant for the stem cell field, establishing a balanced federal policy for hES cell research must remain a priority. Such a policy is essential to enable US researchers to remain competitive in hES cell research, both in terms of basic research and therapeutic opportunities. Although it is perhaps unavoidable that individual state governments will set restrictive policies for stem cell research within their borders - several states have already done so - a liberal policy at the federal level could also soften the tone of hES cell debate and promote greater acceptance of such research within the US. 